\title{
Community-based Crisis Management Model Focusing on the Process of Relief and Rescue in Natural Disasters in Iran \\ Ebrahim Babaei Rayeni ${ }^{1} \mathbb{\infty}$, Mohammad Mehdi Poursaeed ${ }^{2} \oplus$, Mehdi Kazemi ${ }^{3} \oplus$, Mehdi Ebrahimi Nejad Rafsanjani ${ }^{3}$
}

Date of submission: 18 Jun. 2021 Date of acceptance: 28 Jun. 2021

Original Article

\begin{abstract}
INTRODUCTION: The increase in the number of natural disasters has made different societies constantly discover and invent solutions to control the adverse effects of disasters with more emphasis on prevention or minimize them by improving the quality of the rescue process (in the response phase). In the last few decades, the need for social participation in order to manage risks has been developing in the form of community-based activities. This study was conducted to present a community-based crisis management model focusing on the process of relief and rescue in natural disasters in Iran, 2020.
\end{abstract}

METHODS: This qualitative study was performed based on the grounded theory method defined by Strauss and Corbin. The statistical population of the study included all crisis management and nongovernmental organizations experts in universities, the Crisis Management Organization, general managers of provincial crisis management, and senior managers of the Red Crescent Society. The samples were selected using the purposive and theoretical method of snowball sampling while taking into account the geographical, climatic, cultural, social, and religious diversity of different regions of the country. As a result, the sample size was obtained at 22 people. The required data were collected through a semi-structured interview. In the analysis of qualitative information, open coding, axial coding, and selective coding were used manually).

FINDINGS: The results of the study showed that the causal conditions of community-based crisis management included "legal obligation", "strategic planning", "attracting public participation", "forming and developing expert teams", and "acting (prevention, preparedness, needs analysis, planning, and response)"; and contextual conditions consisted of "geographical conditions", "social capacity building", and "creating cohesion and empathy". Moreover, intervening conditions involved "general sensitization", "preparation", and "logistics and equipment"; strategies included "risk management", "human resource management", "training (general and professional)" and "barrier removal"; and the consequences of community-based crisis management consisted of "increasing public awareness in the face of emergencies", "reducing the risk of areas "increasing community resilience", "improving the quality of post-disaster assessment", "accelerating the response process", "determining priorities appropriately", "saving the golden time of rescue", "increasing the number of survivors", "accelerating relief operations" "distributing relief items fairly", "improving the quality of rescue operations", "decreasing the amount of damage", "managing resources and facilities properly", "reducing response costs", "decreasing the adverse psychological effects of the disaster", "organized presence of grassroots groups", "eliminating the shortcomings and completing the performance of the responsible agencies", and "increasing the level of public satisfaction".

CONCLUSION: Community-based crisis management is a new and effective approach that its implementation has a positive impact on increasing resilience and thus reducing the vulnerability of communities. The proper and successful implementation of the community-based approach requires structural changes, amendment of laws, and development of relevant bylaws. It also needs measures that should be implemented at the national level, in the country's crisis management system, and at the local level.

Keywords: Crisis Management; Community-based; Rescue Process; Natural Disasters.

How to cite this article: Babaei Rayeni E, Poursaeed MM, Kazemi M, Ebrahimi Nejad Rafsanjani M. Community-based Crisis Management Model Focusing on the Process of Relief and Rescue in Natural Disasters in Iran. Sci J Rescue Relief 2021; 13(4): 302-11.

\section{Introduction}

oday, the world is exposed to unprecedented natural disasters. An average of 352 million people was exposed to natural disasters annually within 2004-2019 (1). Therefore, one of the issues that most accident-prone countries, including Iran,

1. PhD in Crisis Management, Shahid Bahonar University of Kerman, Kerman, Iran

2. Assistant Professor, Shahid Bahonar University of Kerman, Kerman, Iran

3. Associate Professor, Shahid Bahonar University of Kerman, Kerman, Iran

Corresponding author: Mohammad Mehdi Poursaeed, Email: poursaeed@uk.ac.ir 
are dealing with is natural disasters (2). The situation of countries in terms of accidents can be explained in two ways (researcher). According to the first method, which is based on the frequency of disasters and their adverse effects (e.g., death tolls and damage severity), Iran is one of the 10 most accident-prone countries in the world and takes the 4th stand (3). The second and most up-to-date method in ranking countries is the "Index for Risk Management" and indicates that the risk index is high in Iran (equivalent to 5), and the degree of exposure of this country is determined at 6.2 based on the mentioned index. The natural disaster index in Iran is estimated at 6.8, and among the natural hazards, earthquakes and floods with the indices of 9.6 and 6.4 (out of 10) have attracted more attention, respectively (4).

Proper planning to deal with the damage and consequences of disasters, effective policymaking, providing the necessary facilities and resources, formulating appropriate forecasts, preparing appropriate scenarios, and implementing planned actions in the pre-, while-, and post-crisis stages are among the main tasks of governments; however, the manner in which these tasks are performed varies from country to country (2). In this respect, one of the issues that need to be considered when natural disasters occur in today's world is the existence of different statistics of casualties and damages in similar disasters and the same extent and severity. For instance, an earthquake with a magnitude of 6.5 on the Richter scale struck the city of Bam, Kerman Province, Iran, which caused more than 26,000 death tolls and the destruction of the entire city; nevertheless, in Japan, an earthquake measuring 8.1 on the Richter scale with the epicenter of a city of 10 million people left only 12 people injured, which shows the role of planning and humanitarian actions in preventing casualties and financial losses during natural disasters (3). According to the results of studies, there are weaknesses in the planning and management united and based on social and geographical conditions at the time of natural disasters (5).

It is important to learn from unsuccessful national experiences and properly model successful and effective national and international actions and experiences (6). There are two schools of thought about crisis management. One school of thought believes that a top-down system should be created with a precise and defined hierarchy in the body of government, which will normally have a large organization with broad structures (7). Based on this school of thought, contingency planning must be implemented from top to down, from the national level to the regional level and then to the local level. In this case, it is often difficult to support disaster preparedness plans (8). Another school of thought is based on the premise that crisis management will be ineffective without the cooperation of people and citizens. Therefore, crisis management should be internalized in society; accordingly, crisis management has a core and limited center at the top and the rest of the actions are accomplished by citizens (9).

The inhabitants of an area know the value of their area from different aspects and only they can guarantee how these values can be preserved. Community-based crisis management shows how communities manage crises with their participation to create safe, resistant, and resilient societies with strong economies and high quality of life (10). This management system considers local people as a potential capacity whose participation and cooperation are a guarantee, rather than an obstacle, of sustainability. Therefore, if this management method is formulated and implemented based on scientific principles and mutual respect and trust, it will be a suitable lever to ensure the reduction of damages caused by disasters (11).

The review of the literature has shown that a local and comprehensive model of communitybased crisis management in the country has not yet been presented, and this can cause disruption and confusion among officials and respondents in times of crisis. However, using patterns that do not conform to the geographical and cultural conditions of the country will not work efficiently. Consequently, the present study, as far as possible, sought to fill the mentioned research gap and was conducted to present a national model of community-based crisis management focusing on the process of relief and rescue in natural disasters in Iran, 2020.

\section{Methods}

This qualitative study was performed based on the grounded theory method defined by Strauss and Corbin (12). The statistical population of the study included all crisis 
management and non-governmental organizations experts in universities, the Crisis Management Organization, general managers of provincial crisis management, and senior managers of the Red Crescent Society. The samples were selected using the purposive and theoretical method of snowball sampling while taking into account the geographical, climatic, cultural, social, and religious diversity of different regions of the country. The required data were collected through a semi-structured interview. With the formation of the initial categories, the researcher continued sampling until reaching the theoretical saturation stage to complete and describe them more accurately. As a result, the sample size was obtained at 22 people. In the analysis of qualitative information, open coding, axial coding, and selective coding were used manually.

\section{Findings}

The interviewed experts $(n=22)$ were selected from different provinces of Iran and had a mean age of 54 years, bachelor's and higher degree, and appropriate geographical and cultural dispersion. These individuals had work experience of 10-40 years (average 23.86 years) in emergency management at various national and international levels (Table 1).

Table 1. Frequency distribution of interviewees based on degree and experience in disaster management

\begin{tabular}{|c|c|c|c|}
\hline Education & $\begin{array}{c}\text { National disaster management } \\
\text { experience }\end{array}$ & $\begin{array}{c}\text { International disaster management } \\
\text { experience }\end{array}$ & Total \\
\hline Bachelor & 2 & 2 & 2 \\
\hline MA & 6 & 6 & 6 \\
\hline Doctor of Medicine & 2 & 0 & 2 \\
\hline $\mathrm{PhD}$ & 12 & 7 & 12 \\
\hline
\end{tabular}

The coding of experts' interviews with the aim of presenting a national model of community-based crisis management led to the acquisition of 834 free codes that after being analyzed, 17 main categories and 103 sub-categories were extracted. The main categories were divided into general headings of "causal conditions", "contextual conditions", "intervening conditions", "strategies," and "consequences", which are presented in Tables 2, 3,4 , and 5, respectively. It should be noted that the

Table 2. Causal conditions used in the community-based crisis management model

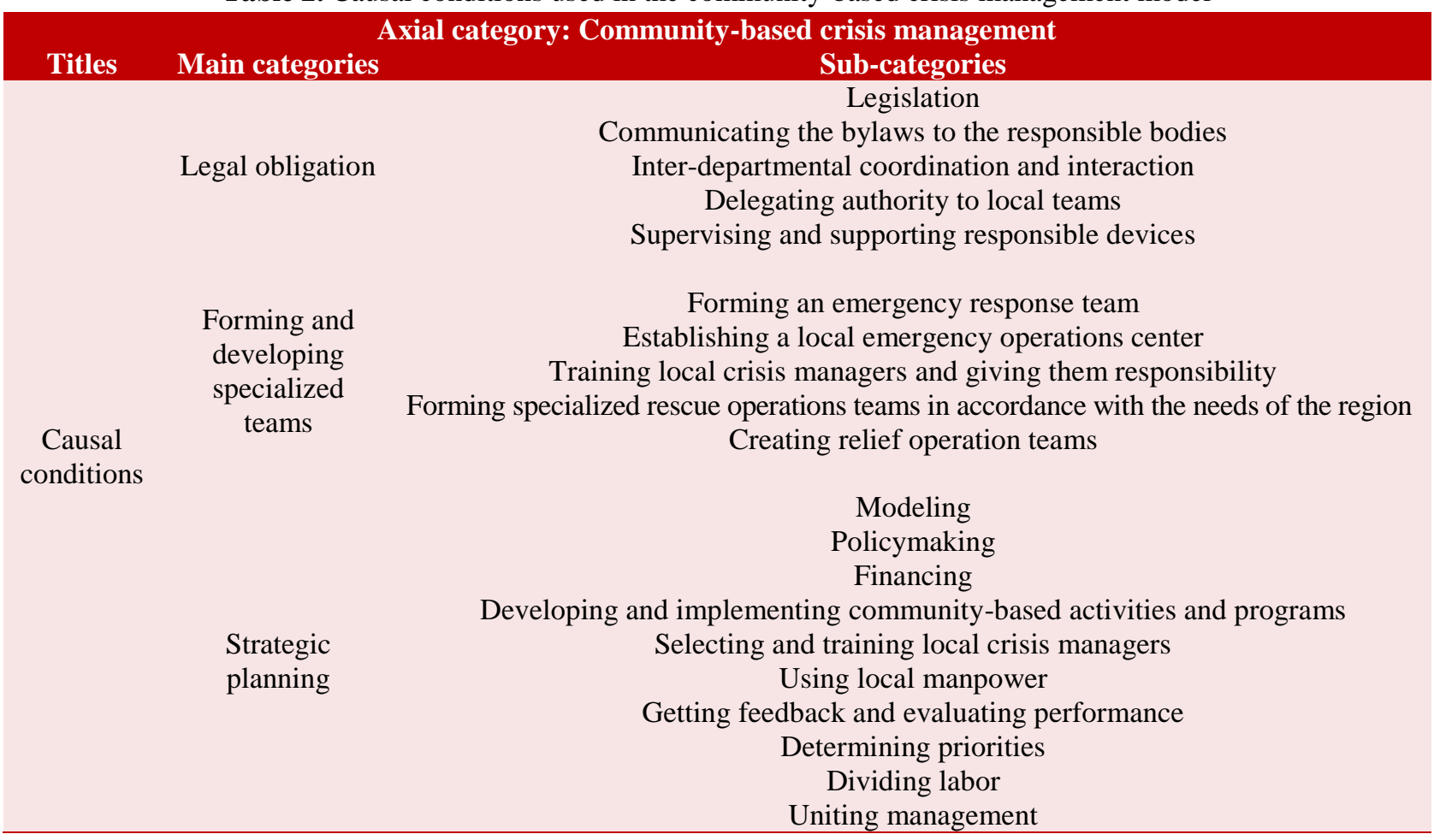




\section{Table 2. Continued}

\section{Public call}

Attracting public participation

Strengthening the context of teamwork

Maximum participation (social systems, grassroots organizations, local associations)

Trust building

Creating motivation

Effective action in line with the National Disaster Risk Reduction and Management Plan

Practical action in line with the National Preparedness and Response Program

Acting

Predicting emergency response planning

Develop a local emergency operation plan

Action in the implementation of the National Reconstruction and Rehabilitation

Program

validity of qualitative data was confirmed by the following three methods (12):

A: Reaffirmation of the obtained data by the interviewees;

B: Analysis of competing hypotheses; and
C: Confirmation of data validity by experts (re-coding of the interviews and final agreement on how to perform it by two judges and approval of the extracted codes by five crisis management specialists).

Table 3. Contextual and intervening conditions used in the community-based crisis management model

\begin{tabular}{|c|c|c|}
\hline \multicolumn{3}{|c|}{ Axial category: Community-based crisis management } \\
\hline Titles & Main categories & Sub-categories \\
\hline \multirow{10}{*}{$\begin{array}{l}\text { Contextual } \\
\text { conditions }\end{array}$} & & Geographical and climatic diversity of the country \\
\hline & Geographical conditions & Study of special conditions of the region \\
\hline & & Regional risk assessment \\
\hline & \multirow{5}{*}{$\begin{array}{l}\text { Creating cohesion and } \\
\text { empathy }\end{array}$} & Strengthening the sense of altruism \\
\hline & & Paying attention to common values \\
\hline & & Cultural, religious, and social adaptation and interaction \\
\hline & & Coordination and cohesion of popular teams \\
\hline & & Synergy of government agencies and grassroots institutions \\
\hline & \multirow{2}{*}{ Social capacity building } & Development of public benefit activities \\
\hline & & Development of social responsibility \\
\hline \multirow{14}{*}{$\begin{array}{l}\text { Intervening } \\
\text { conditions }\end{array}$} & \multirow{9}{*}{ Logistics and equipment } & Operational exercises and dynamization \\
\hline & & $\begin{array}{c}\text { Improvement of the mental and psychological readiness of } \\
\text { the members }\end{array}$ \\
\hline & & Strengthening motivation \\
\hline & & Preparation of rescue operation equipment \\
\hline & & Provision of relief items \\
\hline & & Personal protective equipment \\
\hline & & Storage place for equipment and relief items \\
\hline & & Communication equipment \\
\hline & & Logistical support and assurance \\
\hline & & Degree of country's disaster-prone \\
\hline & & Reminding past disasters \\
\hline & General sensitization & Psychological sufferings resulting from disasters \\
\hline & & Depth of damage from past disasters \\
\hline & & Awareness of the types of crises \\
\hline
\end{tabular}


Table 4. Strategies used in the community-based crisis management model

\begin{tabular}{|c|c|c|}
\hline \multicolumn{3}{|c|}{ Axial category: Community-based crisis management } \\
\hline Titles & Main categories & Sub-categories \\
\hline \multirow{27}{*}{ Strategies } & & Selecting people properly \\
\hline & & Organizing human resources \\
\hline & & Defining duties and responsibilities \\
\hline & Human resource & Determining the hierarchy \\
\hline & management & Creating a communication network between members \\
\hline & & Explaining the role of leadership in the team \\
\hline & & Unity of command \\
\hline & & Establishing an incident command system \\
\hline & & Identifying and ranking disasters \\
\hline & & Implementing disaster prevention programs \\
\hline & Pick monnement & Risk reduction measures \\
\hline & Risk management & Implementing readiness promotion programs \\
\hline & & $\begin{array}{l}\text { Drawing a risk map and formulating an operational plan for the area } \\
\text { Predicting safe gathering places and emergency accommodation }\end{array}$ \\
\hline & & Develoning anpropriate and standard training proorams \\
\hline & & Practicality and comprehensibility of the training \\
\hline & Training (general and & Localizing training according to local conditions \\
\hline & specialized( & Hiring the right instructors \\
\hline & & Continuity in implementing educational programs \\
\hline & & Paying attention to the dynamics of training \\
\hline & & Removing structural barriers \\
\hline & & Removing legal barriers \\
\hline & & Removing political obstacles \\
\hline & Rarrier removal & Removing individual barriers \\
\hline & Barrier removal & Removing social barriers \\
\hline & & Removing economic barriers \\
\hline & & Removing administrative barriers \\
\hline & & Removing cultural barriers \\
\hline
\end{tabular}

Table 5. Consequences used in the community-based crisis management model

\begin{tabular}{|c|c|c|}
\hline \multicolumn{3}{|c|}{ Axial category: Community-based crisis management } \\
\hline Titles & Main categories & Sub-categories \\
\hline \multirow{20}{*}{ Consequences } & \multirow{18}{*}{$\begin{array}{c}\text { Positive } \\
\text { consequences }\end{array}$} & Increasing public awareness in the face of emergencies \\
\hline & & Reducing the risk of areas \\
\hline & & Increasing community resilience \\
\hline & & Improving the quality of post-disaster assessment \\
\hline & & Accelerating the response process \\
\hline & & Determining priorities appropriately \\
\hline & & Saving the golden time of rescue \\
\hline & & Increasing the number of survivors \\
\hline & & Accelerating relief operations \\
\hline & & Distributing relief items fairly \\
\hline & & Improving the quality of rescue operations \\
\hline & & Reducing the extent of damages \\
\hline & & Managing resources and facilities properly \\
\hline & & Reducing response costs \\
\hline & & Decreasing adverse psychological side effects \\
\hline & & Organized presence of grassroots groups \\
\hline & & Eliminating shortcomings and completing the operation of responsible devices \\
\hline & & Increasing public satisfaction \\
\hline & \multirow{2}{*}{$\begin{array}{c}\text { Negative } \\
\text { consequences }\end{array}$} & Likely increase in reactor population \\
\hline & & $\begin{array}{l}\text { Possibility of inappropriate recruitment of team members } \\
\text { Possibility of inability to control emotions }\end{array}$ \\
\hline
\end{tabular}




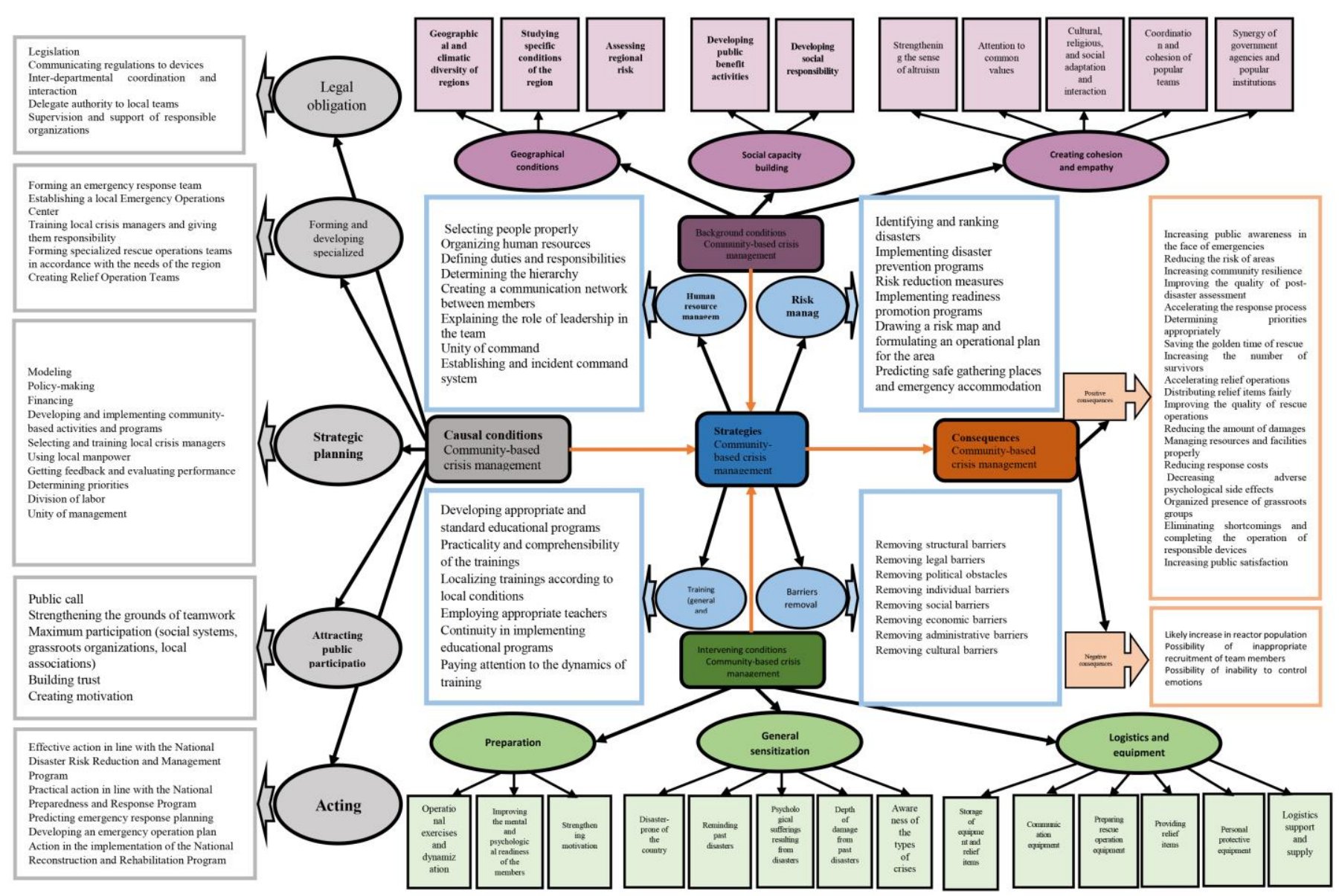

Figure 1. Community-based crisis management model focusing on the rescue process in natural disasters in Iran

The careful and comprehensive analysis of the titles and main and sub-categories extracted in different stages of coding led to the provision of the national model of community-based crisis management with a focus on the process of relief and rescue in natural disasters in Iran (Figure 1).

\section{Discussion and Conclusion}

One of the reasons for the high death tolls and extensive damages in crises is the weakness in planning and management united and baes on the social and geographical conditions at the time of natural disasters $(5,8)$. Among the issues that have been considered in community-based crisis management are empowering local people and groups, recognizing regional disasters, planning to eliminate potential risks, raising the awareness and preparedness of local communities in the face of emergencies, and similar measures that are accomplished by public participation (7). Numerous researchers have emphasized the importance of crisis management and the rescue and relief process; however, to the best of our knowledge, there are very few studies that have consistently and comprehensively addressed the community-based approach to crisis management.

The ignorance of the appropriateness of the crisis management model with local and regional considerations is one of the most important issues that has increased the range of adverse effects of disasters (researcher). In this regard, it is highly considerable to find a way in crisis management (model presentation) that not only is in line with management science and sociology but also explains a reasonable, appropriate, and optimal way for the participation and responsibility of people in a region in the better management of their affairs and the community (communityoriented) in emergencies, which can in addition to the development of related sciences, lead emergency decision-makers to improve management productivity thoroughly (researcher).

The implementation of community-based crisis management in the country is necessary and 
practical (feasible) that in this regard it is necessary to pay special attention to the causal conditions, contextual conditions, intervening conditions, and strategies extracted from the present study (which have often been explained and compiled according to the provisions of the Crisis Management Law, approved by the Islamic Consultative Assembly in August 2019) and achieve the explained consequences with its correct and principled implementation (researcher).

Liu et al. (2016) have mentioned that legislation, social participation, financing, management unity, trust-building, and developing an emergency response plan are necessary for community-based crisis management (9), which confirmed the causal conditions extracted in the present study. Patterson et al. (2020) stated that in order that crisis management be effective, it is necessary to provide its basic backgrounds, including interdepartmental coordination and interaction, delegating authority, supervision and support, forming emergency response team, establishing local emergency operations center, training local crisis managers, creating specialized rescue operation teams appropriate to the needs of each region, strategic planning, developing and implementing community-based activities and programs, applying local human resources, attracting public participation, acting effectively in line with the National Disaster Risk Reduction and Management Program, developing a local emergency response plan, and acting on the implementation of the National Reconstruction and Rehabilitation Plan (13).

Kreitner (2020) has indicated that the prerequisites for community-based crisis management are social participation, delegation, financing, trust-building, and motivation (14). Bing et al. (2013) concluded that the prerequisites for community-based crisis management were social responsibility, group participation, legal support, continuous monitoring, and strategic planning (15). Wenger (1986) has stated that crisis management teams can be trained, similar to sports teams or firefighting teams, and convince them to practice and exercise in order to increase "teamwork experience", "effectiveness", and "reaction speed". At this stage, the use of "simulation techniques", "practical exercise", and "imitation" is highly beneficial.

Top management should support such exercises to increase people's motivation to play their roles and make trainers realize the importance of their work; therefore, effective and appropriate systems should be used to reward employees' efforts in this regard so that they become encouraged to practice hard to deal with the crisis (16). Disaster planning takes place within a system of policies. Thomas R. Dye (1995) divided these activities into four categories, namely policy formulation, policy selection, policy implementation, and policy evaluation (17). Based on these results, it can be said that in order that community-based crisis management become possible in the country and lead to effective results, its initial and causal conditions, including 5 basic actions consisting of the above 30 functions, should be included in the agenda (researcher).

In confirmation of the contextual conditions, Amini Hosseini and Izadkhah (2020) stated that strengthening community-based approaches to crisis management in today's society is a necessity, and the conditions for such an action need to be provided in the society, including planning and coordination based on geographical and climatic conditions of any region and community, strengthening the sense of friendship, coordination and cohesion of local teams, and social responsibility (18). Keritner (2020) mentioned developing social activities, creating shared values, strengthening local identity, and interacting in cultural and social dimensions as necessary conditions for creating and strengthening community-based crisis management (14).

Bing et al. (2013) have concluded that the necessary condition for community-based crisis management is social responsibility and group participation (15). In this regard, Tanwattana (2018) has stated that community-based crisis management is a new approach in crisis management for the participation of all segments of society and is one of the important approaches in the field of disasters. Moreover, since this approach includes community-based components, it has a beneficial effect on reducing vulnerability, and therefore, promoting and increasing resilience. They indicated that community-based crisis management depends on the provision of its context in each community, among which are regional conditions, cohesion and empathy, cultural and social adaptation, camaraderie, accountability, and development of public benefit activities (19). Consequently, based on the obtained results, can be said that it is necessary to provide the context for 
this type of activity and management in society in order to succeed in community-based crisis management; in this respect, apart from the causal conditions, the above-mentioned contextual conditions, including 10 operational actions in the form of 3 basic programs, should also be considered (researcher).

In line with the cases obtained from intervening conditions in the current study, Falk (2013) has stated that in the community-based approach, in addition to identifying the threatening dangers by residents of local communities, it is tried to invite active and influential individuals and groups of communities to work and play a role in all stages of the crisis management cycle and also provide the necessary conditions to increase the capacity of local individuals and groups to deal with the crisis, including exercise and dynamism, citizens' psychological readiness, team equipment preparation, relief equipment provision, attention to logistics, and informing citizens about various crises in different situations (20). In this regard, Patterson et al. (2010) have indicated that local people, who see their lives and property at risk of injury, compared to those who do not have such feelings, are more willing to participate in preparative and responsive activities to crises and natural disasters (21). Therefore, it is required to provide conditions for local people to enter the category of crisis management, including the psychological readiness of local teams, creation of motivation to learn, support and equipment, and public sensitivity of each community to the occurrence of crises (1).

According to the obtained results, it can be said that in order to have effective crisis management that is community-based, it is necessary to simultaneously consider the causal and contextual conditions along with the measures explained as intervening conditions (including 14 important and effective functions that are presented in the form of 3 basic actions of sensitization, preparation, and logistics and equipment) (researcher). In confirmation of the strategies obtained in this study, Pourezzat et al. (2013) have reported that the main purpose of community-based crisis management is to involve local and indigenous forces in the processes of planning, policymaking, coordination, control, and organization of the crisis management with the guidance of the government. They stated that during the implementation of these processes, attention should be paid to basic strategies, such as organizing individuals, paying attention to hierarchy and team command, identifying and distinguishing types of risks, considering the importance of preparedness, training properly and appropriate to the conditions, and removing structural, legal, and executive barriers (22).

Tanwattana and Toyoda (2018) have concluded that in order to succeed in implementing community-based crisis management, it is necessary to adopt such strategies as selecting people properly, organizing the workforce, establishing a communication network among members, unity of command, identifying and ranking various disasters in each region, forecasting safe gathering places and emergency accommodation, training human resources, providing pieces of training appropriate to local conditions, and removing legal and cultural barriers (23). Therefore, it can be stated that to succeed in community-based crisis management, various strategic plans are required that were mentioned above and identified in 28 strategic activities specified under 4 basic actions. It should be noted that simultaneous attention to causal conditions, contextual conditions, intervening conditions, and strategies would lead to desirable outcomes (researcher).

In confirmation of the results of this study, Fernández-Giménez et al. (2015) indicated that community-based, people-based, and developmentbased crisis management consider the vulnerability of people toward crises (24). This approach empowers individuals by introducing vulnerable root causes while transforming political, economic, and social structures that lead to inequality and nondevelopment (6). Zahari (2013) has concluded that success in achieving the goals of communitybased crisis management would reduce the consequences and damages caused by natural disasters (25). In this regard, Borrini et al. (2000) have stated that in the community-based crisis management system, local people are considered a potential source whose participation and cooperation are a guarantee of sustainability rather than an obstacle to it (11). Consequently, if this management approach is developed and implemented based on scientific principles and mutual respect and trust, it will be a suitable lever to ensure the reduction of damages caused by disasters (26) and lead to positive consequences, such as reducing risks, making the community resilient, accelerating accountability, prioritizing 
actions, better rescuing and relieving, decreasing damages and costs, determining tasks of people's groups, eliminating shortcomings of responsible organizations (27). Tanwattana (2018) also believes that community-based crisis management is designed to involve all segments of society and has a positive effect on reducing vulnerability and thus increasing resilience (19). According to the results of the current study, community-based crisis management, taking into account the causal conditions, contextual conditions, intervening conditions, and strategies, would lead to the 21 outcomes mentioned above (researcher).

So far, dealing with traditional methods and not paying attention to social issues has led to less success in natural disaster management (researcher). Ebrahimi Nejad (1397), referring to the issue of floating (island) management, considers the reason for this problem as "the government's limited capacity to provide services"; and emphasizes the "high and potential capacity of society" and "managerial ability of popular managers" (28). Regarding, the damages caused by natural disasters are greatly reduced and the psychological and social problems of the affected people are decreased by relying on communitybased and participatory approaches (18). In the community-based approach, in addition to identifying risks by local residents, efforts are made to call influential individuals and groups of communities to play a role in all stages of the crisis management cycle (20). The main purpose of this approach is to involve indigenous and local forces in the processes of planning, policymaking, coordination, control, and organization of crisis management under the leadership of the government (22). This capability is created in the shadow of capacity building (25). Among the successful ways are strengthening the spirit of cooperation and motivating participation among the individuals. Local people who see their lives and property at risk of injury, compared to those who do not have such feelings, are more motivated and willing to participate in preparedness and response to crises and natural disasters (13).

Experts believe that if community-based crisis management initiatives are considered a key element in broader crisis prevention processes, sustainable development planning, and institutionalization, they will be much more effective than when they are merely considered a local project with short-term goals for disaster preparedness (29). In this respect, not only it is required to plan to deal with crises but also a community-based (bottom-up) approach should be seriously included on the agenda of governments (18).

According to the proposed model, in order to benefit from the participation of all groups in the field of crisis management and review the experiences in involving citizens and local communities in different stages of the crisis management cycle, it seems that the country's crisis management organization will provide the context for increasing the effectiveness of these approaches and its greater compliance with the principles set out in the community-based approach to disaster management. Consequently, the measures needed to be adopted to successfully implement community-based approaches to crisis management can be divided into two parts. The first part consists of the measures to be taken at the national level and the country's crisis management system and needs structural changes, and amendments of laws, and development of the relevant bylaws. The second part is the actions that need to be taken at the local level and neighborhood management.

\section{Acknowledgments}

The authors of the present paper would like to sincerely thank all those who contributed to this research.

\section{Conflict of Interests}

Authors declared no conflict of interests regarding the publication of the present study.

\section{References}

1. Räsänen A, Lein H, Bird D, Setten G. Conceptualizing community in disaster risk management. Int J Disaster Risk Reduct 2020; 45:101485.

2. Sarabia MM, Kägi A, Davison AC, Banwell N, Montes C, Aebischer C, Hostettler S, et al. The challenges of impact evaluation: Attempting to measure the effectiveness of community-based disaster risk management. Int $\mathbf{J}$ Disaster Risk Reduct 2020; 49:101732.

3. Kamali Y, Mirzaei J. Comparison of crisis management structure in Iran, Japan, India, and Turkey. J Strateg Stud, Public Policy 2017; 7(25):246-269. (In Persian)

4. Thow, A., Vernaccini, L., Nika, A., Poljansek, K., Galimberti, L. and Dalla Valle, D., Inform report. Shared evidence for managing crises and disasters, Publications Office of the European Union, Luxembourg, 2021, ISBN 978-92-76-39355-9, 


\section{JRC125620.}

5. Pour-Aghajan, Mehdi; Mehdi Pour-Aghajan and Yousef Beigzadeh, Assessing Organizational Transformability and Its Impact on Crisis Management (Case Study: East Azerbaijan Company), Fourth National Conference on Management, Economics and Accounting, Tabriz, East Azerbaijan Industrial Group Organ Manag. University of Tabriz; 2015. (In Persian)

6. Ashouri A, Khayatian M, Farzadi M. Investigating the role of community-based in crisis management. Conference on Civil Engineering, Architecture, and Urban Planning in the Islamic world, Tabriz. 2018. (In Persian)

7. Karimi Kh, Taqhilou AA. Community-based crisis management is a path to sustainable development. Knowledge of crisis prevention and management. 2020; 10(1):73-59. (In Persian)

8. Azad MA, Uddin K, M. S., Zaman, S., \& Ashraf, M. A. Community-based Disaster Management and Its Salient Features: A Policy Approach to Peoplecentered Risk Reduction in Bangladesh. AsiaPacific Journal of Rural Development, 2019; 29(2), 135-160. (In Persian)

9. Liu Y, Yin K, Chen L, Wang W Liu, Y. A community-based disaster risk reduction system in Wanzhou, China. International Journal of Disaster Risk Reduction, 2016; 19, 379-389.

10. Peng L, Tan J, Deng W, Liu Y. Farmers' participation in community-based disaster management: The role of trust, place attachment, and self-efficacy. Int J Disaster Risk Reduct 2020; 51:101895.

11. Borrini G, Kothari A, Oviedo G, Adrian Ph. Indigenous and Local Communities and Protected Areas: Towards Equity and Enhanced Conservation, Guidance on policy and practice for Co-managed Protected Areas and Community Conserved Areas, World Commission on Protected Areas. 2000

12. Bazargan A. Introduction to qualitative research methods and a combination of common approaches in behavioral sciences. Tehran, Publication: Didar. 2019 (In Persian)

13. Patterson, Olivia; Fredrick Weil \& Kavita Patel. The Role of Community Disaster Response: Conceptual Models, Springer, 2020; 29, P.127-141.

14. Sikich GW. All hazard crisis management Planning: Logical management systems. 2020

15. Bing MN, Davison H, Minor I, Novicevic M, Frink D. The relationship between organizational structure and crisis management. J Vocat Behav 2013; 17(2).

16. Wenger DS. Community response to disaster: functional and structural alterations. In E. L. Quarantelli. Disaster: theory and research. 47
Beverly Hills, CA: Sage. 2018

17. Andrew M. Revisiting community-based disaster risk management. In Environmental Hazards; Routledge, 2018; 42-52

18. Amini Hosseini K, Izadkhah Y. From Earthquake and safety school drills to safe school-resilient communities: A continuous attempt for promoting community-based disaster risk management in Iran. Int J Disaster Risk Reduct 2020; 45:101512. (In Persian)

19. Tanwattana P. Systematizing Community-Based Disaster Risk Management (CBDRM): Case of urban flood-prone community in Thailand upstream area. Int J Disaster Risk Reduct 2018; 28,798-812.

20. Falk K. Preparing for Disaster: A Community Based Approach, 2nd Rev. Danish Red Cross, Copenhagen. 2013

21. Patterson O, Weil F, Patel K. The Role of Community in Disaster Response: Conceptual Models. Popul Res Policy Rev 2010; 29:107-111.

22. Pourezzat A, Firouzpour A, Sadabadi AA. Studying and comparison of community-based approach to crisis management in selected countries. J Manag Gov 2013;1(0):37-52. (In Persian)

23. Tanwattana P, Toyoda Y. Contributions of gaming simulation in building community-based disaster risk management applying Japanese case to flood prone communities in Thailand upstream area. Int $\mathbf{J}$ Disaster Risk Reduct 2018; 27:199-213.

24. Fernández-Giménez ME, Batkhishig B, Batbuyan B, Ulambayar T. Lessons from the Dzud: Community-Based Rangeland Management Increases the Adaptive Capacity of Mongolian Herders to Winter Disasters. World Development 2015; 68: 48-65.

25. Zahari RK, Ariffin R N R. Community-Based Disaster Management in Kuala Lumpur. Procedia Soc Behav Sci 2013; 85:493-501.

26. Van Niekerk D, Nemakonde LD, Kruger L, ForbesGenade K. Community-based disaster risk management. In Handbook of disaster, research Springer, Cham 2018: 411-429.

27. Sarabia MM, Kägi A, Davison AC, Banwell N, Montes C, Aebischer C, Hostettler S, et al. The challenges of impact evaluation: Attempting to measure the effectiveness of community-based disaster risk management. Int J Disaster Risk Reduct 2020; 49:101732.

28. Ebrahimi Nejad M. Crisis Management. Kerman, Shahid Bahonar University 2018. (In Persian)

29. Motahari Z, Rafeian M. Explaining a model to improve crisis risk management with a communitybased approach, case study: one of the local communities in Tehran. Armanshahr Architecture and Urban Planning 2016: 17:389-401. (In Persian) 